\title{
Exploring the attitudes of 11-14 year olds to physical activity: a focus group study
}

\author{
A. Carlin ${ }^{1}$, M. H. Murphy ${ }^{2}$ and A. M. Gallagher ${ }^{1}$ \\ ${ }^{1}$ Northern Ireland Centre for Food and Health, University of Ulster, Coleraine, BT52 1SA and \\ ${ }^{2}$ Ulster Sports Academy, University of Ulster, Jordanstown, BT37 OQB
}

The prevention and management of obesity is a major public health priority, with almost one third of children in Northern Ireland now classified as overweight or obese ${ }^{(1)}$. The promotion of physical activity is often a key focus of public health efforts to reverse such trends in childhood obesity ${ }^{(2)}$. The aim of this study was to gain an insight into the attitudes and thoughts of young people (aged 11-14 years) in relation to physical activity and to explore what approaches this age group would find most helpful in encouraging them to increase or maintain their current levels of physical activity.

180 pupils were recruited from 3 post-primary schools. All participants completed the PAQ-C ${ }^{(3)}$ and underwent measurements of height and weight. A sub-sample ( $n=64 ; 39$ females; 25 males) of participants were selected to take part in focus group discussions, with groups formed based on physical activity scores derived from the PAQ-C (i.e. low or high active groups). 9 focus groups with five to eight participants in each group were conducted; 3 groups of 'highly active' participants and 6 groups of 'low active' participants. Participants' views on physical activity, including current influences and how best to promote physical activity, were explored using a semi-structured topic guide. Focus groups were audio-recorded, transcribed verbatim, coded and analysed using thematic analysis ${ }^{(4)}$.

Major themes emerged within two main areas, namely (1) current influences on physical activity and (2) how to increase participation in physical activity. These themes are highlighted below, supported by quotes from participants: Example quotes from participants

Current influences

Friendship

Family

Consequences of not taking

part

Changing priorities

Cost and access to resources

How to increase participation

Try new activities

Increase school based activities

Include technology

Provide rewards and incentives
“... see I don't really do that much, but I'd say it's like say my friends are doing stuff I'd go do it with them."

"My like sister and my like mum are always like pushing, my mum like pushes me to do like different sports..."

"You're more likely to be sick and have like health problems and stuff",

"... there's other things that you would want to do and prioritise and then, you know, activity just falls off the list."

"You're more likely to do a sport that you don't have to pay lots for..."

“... if they weren't all sports. .. because some people don't like always like do a particular sport because you have to actually be good at it."

"It would give you a chance to relax in the middle of the day, relax before the final classes..."

"...you had to take track of all the sport and then like show it to someone at the end, you would be trying to do more to like show off" "You got points for putting the effort into it... like even if you're not the best person that you still tried your best."

A number of key influences on current physical activity were identified including a number of barriers, such as time, cost and access to resources, which participants felt needed to be overcome to facilitate their participation in physical activity. Such influences should be considered, alongside suggestions from participants on how best to promote physical activity, within future public health initiatives targeted at promoting physical activity among children and young people.

1. Department of Health, Social Services and Public Safety (2012) HealthSurvey Northern Ireland 2011/12.

2. Van Sluijs EMF, McMinn AM \& Griffin SJ (2007) Br Med J 335, 703.

3. Kowalski WC, Crocker P \& Donen R (2004) The Physical Activity Questionnaire for Older Children (PAQ-C) and Adolescents (PAQ-A) Manual

4. Braun V \& Clarke V (2006) Qual Res Psychol 3, 77-101. 